\title{
Design and Fabrication of Concentric Tube Heat Exchanger
}

\author{
Kadari Deepika \\ Student, Mechanical Engineering Department \\ Warangal Institute of Technology \&Science, Warangal, Telangana, India \\ Elumagandla Surendar \\ Head of the department, Mechanical Engineering Department, \\ Warangal Institute of Technology \&Science, Warangal, Telangana, India.
}

\begin{abstract}
In this paper a Double pipe Heat exchanger is designed and fabricated with $1.8 \mathrm{~m}$ long copper pipe and galvanized iron pipe is utilized for tube and shell materials. The Experimental analysis is conducted by passing hot water in inner pipe and cold water in the annulus. The experiment is performed with both parallel and counter flow configurations under three mass flow rates conditions where cold water flow rate and hot water flow rate are changed. Inlet and Outlet temperatures are measured by using thermocouples at various locations. The Overall heat transfer coefficient is calculated and compared with both parallel and counter flow for theoretical and actual performance of heat exchanger and found counter flow heat transfer is increased than parallel flow. The research takes in to account of different nano fluids for effective heat transfer in Heat exchanger.
\end{abstract}

Keywords-Double pipe heat exchanger, Design methodology, Fuid flow fluent.

\section{INRODUCTION}

Heat exchangers are devices used to transfer heat energy from one fluid to another. Typical heat exchangers experienced by us in our daily lives include condensers and evaporators used in air conditioning units and refrigerators. Boilers and condensers in thermal power plants are examples of large industrial heat exchangers. There are heat exchangers in our automobiles in the form of radiators and oil coolers. Heat exchangers are also abundant in chemical and process industries. There is wide variety of heat exchangers for diverse kinds of uses; hence the construction also would differ widely. However, in spite of the variety, most heat exchanger can be classified into some common types based on some fundamental design concepts. In a Heat exchanger the heat between two fluids of different temperatures that are separated by a solid wall. The temperature gradient or the differences in temperature facilitate this transfer of heat. Transfer of heat happens by three principle means: radiation, conduction and convection. In the use of heat exchangers radiation does take place. However, in comparison to conduction and convection, radiation does not play a major role. Conduction occurs as the heat from the higher temperature fluid passes through the solid wall. To maximize the heat transfer, the wall should be thin and made a very conductive material. The biggest contribution to heat transfer in a heat exchanger is made through convection. In a heat exchanger, forced convection allows for the transfer of heat of one moving stream to another moving stream. With convection as heat is transferred through the pipe wall it is mixed into the stream and the flow of the stream removes the transferred hear. This maintains a temperature gradient between the two fluids. The double-pipe heat exchanger is one of the simplest types of heat exchangers. It is called a double-pipe exchanger because one fluid flows inside a pipe and the other fluid flows between the pipe and another pipe that surrounds the first. This is a concentric tube construction. Flow in a double-pipe heat exchanger can be co-current or counter-current. There are two flow configurations: co-current is when the flow of the two streams is in the same direction, counter current is when the flow of the stream is in opposite directions. A Double-pipe heat exchangers are commonly used in applications involving relatively low flow rates and high temperatures or pressures, for which they are well suited. Other advantages include low installation cost, ease of maintenance, and flexibility. Hairpins can easily be added to or 
removed from an existing battery, or arranged in different series-parallel combinations to accommodate changes in process conditions. Simple un-finned double-pipe exchangers tend to become unwieldy. They are also relatively expensive per unit of heat transfer surface. Much larger heat-transfer areas are practical using multi-tube units with finned tubes. In fact, multi-tube hairpin exchangers with heat-transfer areas in excess of $12000 \mathrm{ft}^{2}$ have been built and are commercially available. A double pipe heat exchanger, in its simplest from is just one pipe inside another larger pipe. One fluid flows through the inside pipe and the other flows through the annulus between the two pipes. The wall of the inner pipe is the heat transfer surface. The pipes are usually doubled back multiple times as shown in the diagram at the left, in order to make the overall unit more compact. The term 'hairpin heat exchanger' is also used for a heat exchanger of the configuration in the diagram. A hairpin heat exchanger may have only one inside pipe, or it may have multiple inside tubes, but it will always have the doubling back feature shown. Some heat exchanger manufacturers advertise the availability of finned tubes in a hairpin or double pipe heat exchanger. These would always be longitudinal fins, rather than the more common radial fins used in across flow finned tube heat exchanger.

\section{HEAT EXCHANGER DESIGN METHODOLOGY}

Heat exchanger design methodology, involves the following major design considerations

1. Process /design specifications.

2. Thermo hydraulic design.

3. Flow-inducted vibration in case of cell and tube heat exchanger and individual fin tube and bare tube heat exchanger.

4. Mechanical design.

5. Cost and manufacturing considerations.

6. Trade-off factors and system based optimization.

Most of these considerations are dependent on each other and should be consider simultaneously to arrive at the optimum exchanger design.

Modelling of double pipe heat exchanger in PRO-E software

Outer pipe and inner pipe can be modelled by following steps

1. Sketching on respective planes with inner and outer diameter and length followed by sweep, protrusion to their perpendicular axis.

2. Thus forms hollow circular pipes

3. The arc command is used for bend pipe and followed by thin protrusion starting from geyser

4. For varying diameters at the pipe cut tool is used

5. A datum plane is selected to draw the remaining pipe.

6. Mirror command is used to for galvanized pipe.

Other parts are modelled according to extrude and saved in ".part"format. 


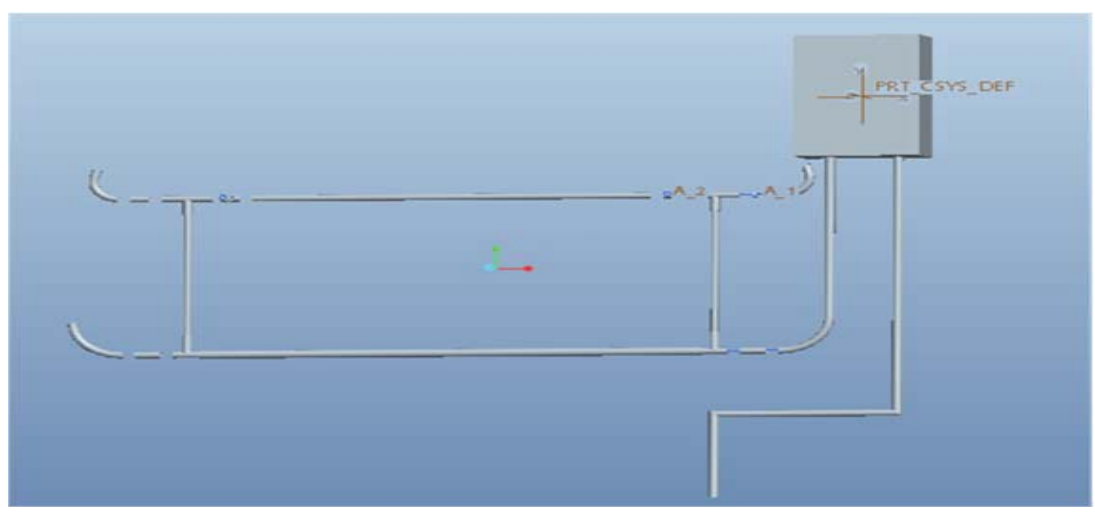

Fig no:1 Design of Heat exchanger in Pro-E

\section{FABRICATION OF HEAT EXCHANGER}

Fabrication of heat exchanger involves different machining process which are based on factor such as material properties, fluid properties, thermocouples. Machining process such as turning, drilling, boring, threading, surface finishing

\section{SPECIFICATIONS FOR FABRICATION}

Mild steel pipe of $0.04 \mathrm{~m}$ Diameter with a length of $1.8 \mathrm{~m}$.

Copper tube of Diameter $0.012 \mathrm{~m}$

Thermocouples

Geyser

Digital meter.

Asbestos Insulation.

3 phase motor.

Valves

OUTER PIPE: It is made of galvanized iron which has a length of $1.8 \mathrm{~m}$ and $40 \mathrm{~mm}$ diameter and is insulated with asbestos lining to avoid heat transfer in to atmosphere. In this pipe cold water is send from water tank through a pipe.

INNER PIPE: It is made of copper surrounded by outer pipe which has inner diameter of $12 \mathrm{~mm}$ and outer diameter with $15 \mathrm{~mm}$.It contains hot water send from geyser by means of a motor

VALVES: These are of 6 in no which are utilized for allowing water in both counter and parallel flow mode by regulating them direction change of fluid is possible through these valves.

GEYSER: Arrangement of geyser is present over the heat exchanger for heating fluid before entering into heat exchanger. It is has a capacity of 1 liter.

THERMOCOUPLES: A thermocouple consists of two dissimilar conductors in contact, which produces a voltage when heated. The size of the voltage is dependent on the difference of temperature of the junction to the parts of the circuit. Thermocouples are widely used type of temperature sensor for measurement and control and can also be used to convert a temperature gradient into electricity. Commercial thermocouples are inexpensive, interchangeable, are supplied with standard connectors, and can measure a wide range of temperatures.

ELECTRIC MOTOR: A single phase motor is used for lifting water from tank to circulate in concentric tube heat exchanger. 


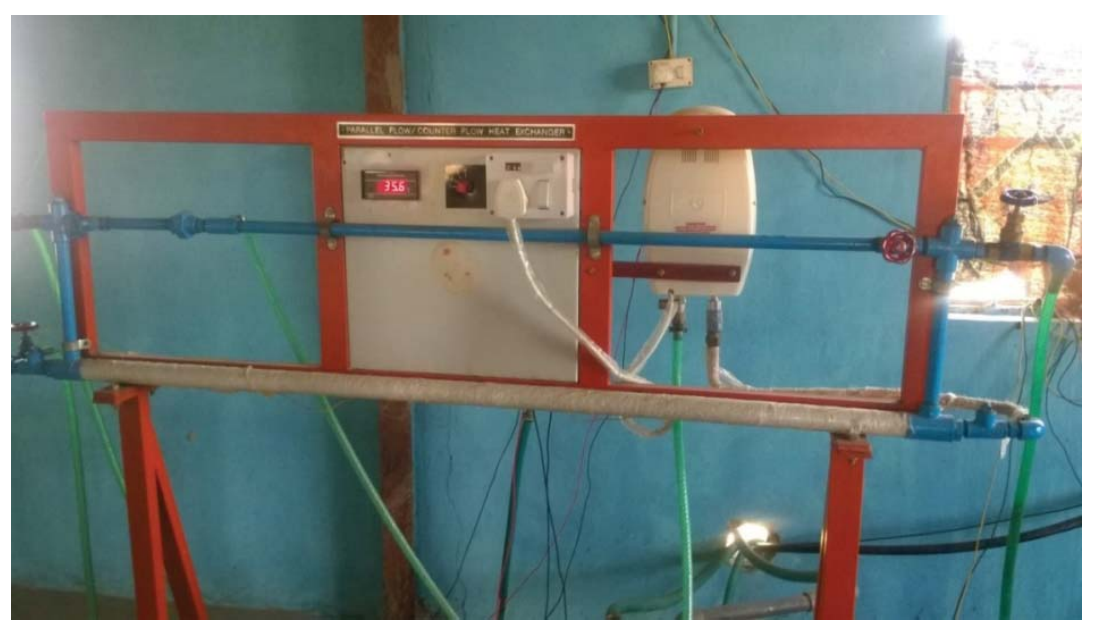

Fig no: 2 Experimental setup

\section{EXPERIMENTAL PROCEDURE:}

The power supply is switched on the electric geyser ensuring that there is adequate water flow through geyser.

- Check the valves are in proper condition for required flow mode

\section{Parallel flow mode}

- Suitable valves are opened $\mathrm{v} 1, \mathrm{v} 3, \mathrm{v} 4 \& \mathrm{v} 2, \mathrm{v} 5$ are closed to operate the heat exchanger in parallel flow mode

- Both the hot and cold-water flows are adjusted to get reasonable temperatures between outlet and inlet streams.

- When the temperature reach study state take the thermocouple readings from the digital meter

\section{Counter flow mode}

- Suitable valves are opened $\mathrm{v} 2, \mathrm{v} 4, \mathrm{v} 5 \& \mathrm{v} 1, \mathrm{v} 3$ are closed to operate the heat exchanger in counter flow mode

- As the valves are opened the cold water direction is changed in opposite direction of hot water

- The remaining temperature readings shown by thermocouples are noted at regular intervals only after steady state condition during flow through the concentric pipe of heat exchanger, Observation table is prepared for calculation.

\section{SIMULATION OF DOUBLE PIPE HEATEXCHANGER}

$>$ Import the geometry in to Fluid fluent solver with IGES / STEP files.

$>$ When it is imported the initial geometry remains as single one so different parts are created to define different boundary conditions

> Different parts are created as shell inlet, shell outlet, tube inlet, tube outlet shell solid and tube solid.

$>$ Sizing is done for the concentric tube by selecting fine mesh.

$>$ Select as update mesh, after meshing completes go to set up.

Up to now geometry and mesh was created. Now the mesh is used to define a Computational fluid dynamics (CFD) simulation. 
$>$ In ANSYS work bench 14.5 CFD module is opened and meshed

$>$ Go to set up and edit as check energy on.

$>$ Select the materials for solid as mild steel and fluid as water.

$>$ Insert boundary conditions for tube fluid.

For cold water inlet give velocity and temperatures with its respected units.

For hot water inlet give the corresponding values as boundary conditions

\section{RELATED WORK}

[1] R.K Shah his elaborate discussion over the classification of heat exchangers has defined the "compact heat exchangers" as one having a surface area density of more than $700 \mathrm{~m}^{2} / \mathrm{m}^{3}$.Such compactness is achieved by providing the extended surfaces i.e. fin on the flow passages which work as the secondary heat transfer area.[2] Folaranmi Joshua Department of Mechanical Engineering, Federal University of Technology studied the process of heat transfer between two fluids through a solid partition. It was designed for a counter-flow arrangement and the logarithmic mean temperature difference (LMTD) method of analysis was adopted. Water was used as fluid for the experiment. [3] Joshi and Webb developed an analytical model to predict the heat transfer coefficient and the friction factor of the offset strip fin surface geometry. To study the transition from laminar turbulent flow they conducted the flow visualization experiments and an equation based on the conditions in wake was developed [4] Michna et al investigated the effect of increasing Reynolds number on the performance of OSFs. He conducted the experiment at Reynolds number between 5000 to120000 and found that both heat transfer and pressure drop increased with increasing Reynolds number, because the effect of vortex shedding and eddy formation at turbulent regime. Operation of OSF heat exchangers under these Reynolds number may be useful in systems where minimizing the heat exchanger size or maximizing the heat transfer coefficient is more important.[5] Reza Aghayari, and Sahar Ghanbari Kaskari investigated the enhancement of heat transfer coefficient and Nusselt number of a nanofluid containing nano particles $\left(\gamma-\mathrm{AL}_{2 \mathrm{O}}\right)$ with a particle size of $20 \mathrm{~nm}$ and volume fraction of $0.1 \%-0.3 \%(\mathrm{~V} / \mathrm{V})$. Effects of temperature and concentration of nanoparticles on Nusselt number changes and heat transfer coefficient in a double pipe heat exchanger with counter turbulent flow are investigated. Comparison of experimental results with valid theoretical data based on semi empirical equations shows an acceptable agreement. Experimental results show a considerable increase in heat transfer coefficient and Nusselt number up to $19 \%-24 \%$, respectively. Also, it has been observed that the heat transfer coefficient increases with the operating temperature and concentration of nanoparticles. [6] N. K. Chavda1, Jay R. Patel2, Hardik H. Patel3, Atul P. Parmar4 Corresponding Author, Associate Professor, Department of Mechanical Engineering, A. D. Patel Institute of Technology, The effect of nanofluid to enhance the heat transfer rate in various heat exchangers is experimentally evaluation.[7] Mr. Vatsal.S.PatelDr.Ragesh. M.E.[Thermal Engg.] Student Department of Mechanical Engineering, S.V.M. Institute of Technology, Bharuch Gujarat.The heat transfer enhancement using nano fluid mainly depends on type of nano particles, size of nano particles and concentration of nano particles in base fluid. In the present paper, an experimental investigation is carried out to determine the effect of various concentration of $\mathrm{Al} 2 \mathrm{O} 3$ nano-dispersion mixed in water as base fluid on heat transfer characteristics of double pipe heat exchanger for parallel flow and 
counter flow arrangement.[8] Suzuki et al [ in order to study the thermal performance of a staggered array of vertical flat plates at low Reynolds number has taken a different numerical approach by solving the elliptic differential equations governing the flow of momentum and energy. The validation of their numerical model has been done by carrying out experiments on a two dimensional system, followed by those on a practical offset strip fin heat exchanger. The experimental result was in good agreement with the performance study for the practical offsetstrip-fin type heat exchanger in the range of Reynolds number of $\operatorname{Re}<800$ [9] Tinaut et al developed two correlations for heat transfer and flow friction coefficients for OSFs and plane parallel plates. The working fluid for OSF was engine oil and water was taken for analyzing the parallel plate channels. By using the correlations of Dittus and Boelter and some expressions of Kays and Crawford they obtained there correlations. For the validationof their results they compared there correlations with correlations of Weitng. Although there were some differences between the results but there correlations have been found acceptable upon comparing their results to the data obtained from other correlations.[10] Manglik and Bergles carried an experimental research on OSFs. They investigated the effects of fin geometries as non-dimensional forms on heat transfer and pressure drop, for their study they used 18 different OSFs. After their analysis they arrived upon two correlations, one for heat transfer and another one for pressure drop. The correlations were developed for all the three regions. They compared there results from the data obtained by other researchers in the deep laminar and fully turbulent regions. There correlations can be acceptable when comparing the results of the expressions to the experimental data obtained by Kays and London.

\section{RESULTS AND DISCUSSIONS}

In this project a concentric tube heat exchanger has been designed and fabricated for the required specifications and a excel spread sheet helps in getting the appropriate results as soon as inputs are given. An experimental analysis is done on the concentric tube heat exchanger and heat transfer coefficient is find out and is compared with theoretical and practical values

\section{PARALLEL FLOW RESULTS}

\begin{tabular}{|c|c|c|c|c|c|}
\hline \multicolumn{2}{|c|}{ Parallel flow } & LMTD & $\begin{array}{c}\text { U } \\
\text { Actual }\end{array}$ & $\begin{array}{c}\text { U } \\
\text { Theoretical }\end{array}$ & $\begin{array}{c}\varepsilon \\
\text { Effectiveness }\end{array}$ \\
\hline \multicolumn{2}{|c|}{ Units } & K & $\mathrm{W} / \mathrm{m}^{2} \mathbf{k}$ & $\mathbf{W} / \mathbf{m}^{2} \mathbf{k}$ & \\
\hline \multicolumn{2}{|c|}{$\begin{array}{c}\text { Mass flow } \\
\text { Rates }\end{array}$} & & & & \\
\hline $\mathbf{m h}$ & $\mathbf{m c}$ & & & & \\
\hline 0.049 & 0.141 & 38.311 & 187.793 & 392.977 & 0.269 \\
\hline 0.094 & 0.091 & 33.981 & 229.726 & 809.248 & 0.245 \\
\hline 0.08968 & 0.0911 & 21.806 & 53.763 & 63.093 & 0.241 \\
\hline
\end{tabular}


COUNTER FLOW RESULTS

\begin{tabular}{|c|c|c|c|c|c|}
\hline \multicolumn{2}{|c|}{ Counter flow } & LMTD & $\begin{array}{c}\mathrm{U} \\
\text { Actual }\end{array}$ & $\begin{array}{c}\mathrm{U} \\
\text { Theoretical }\end{array}$ & $\begin{array}{c}\varepsilon \\
\text { effectiveness }\end{array}$ \\
\hline \multicolumn{2}{|c|}{ Units } & $\mathbf{K}$ & $\mathbf{W} / \mathbf{m}^{2} \mathbf{k}$ & $\mathbf{W} / \mathbf{m}^{2} \mathbf{k}$ & \\
\hline \multicolumn{2}{|c|}{$\begin{array}{c}\text { Mass flow } \\
\text { Rates }\end{array}$} & & & & \\
\hline mh & mc & & & & \\
\hline 0.049 & 0.141 & 36.251 & 325.934 & 395.830 & 0.306 \\
\hline 0.084 & 0.071 & 32.41 & 361.271 & 436.012 & 0.486 \\
\hline 0.051 & 0.135 & 24.36 & 413.171 & 537.837 & 0.320 \\
\hline
\end{tabular}

Effect of mass flow rate on Heat Transfer for Parallel flow

\begin{tabular}{|c|c|c|}
\hline $\begin{array}{l}\text { Mass } \\
\text { flow } \\
\text { rate } \\
(\mathrm{kg} / \mathrm{sec})\end{array}$ & $\begin{array}{l}\text { Theoretical Heat } \\
\text { transfer } \\
\text { coefficient } \\
\left(\mathrm{W} / \mathrm{m}^{2} \mathrm{k}\right)\end{array}$ & $\begin{array}{c}\text { Actual Heat } \\
\text { transfer } \\
\text { coefficient } \\
\left(W / m^{2} k\right)\end{array}$ \\
\hline 0.05 & 392.977 & 187.793 \\
\hline 0.1 & 809.248 & 229.726 \\
\hline
\end{tabular}

Effect of mass flow rate on Heat transfer for Counter flow

\begin{tabular}{|c|c|c|}
\hline $\begin{array}{l}\text { Mass flow } \\
\text { rate } \\
(\mathrm{kg} / \mathrm{sec})\end{array}$ & $\begin{array}{l}\text { Theoretical Heat } \\
\text { transfer } \\
\text { coefficient } \\
\left(\mathrm{W} / \mathrm{m}^{2} \mathrm{k}\right)\end{array}$ & $\begin{array}{c}\text { Actual Heat } \\
\text { transfer } \\
\text { coefficient } \\
\left(W / m^{2} k\right)\end{array}$ \\
\hline 0.049 & 395.830 & 325.934 \\
\hline 0.084 & 436.012 & 361.271 \\
\hline
\end{tabular}




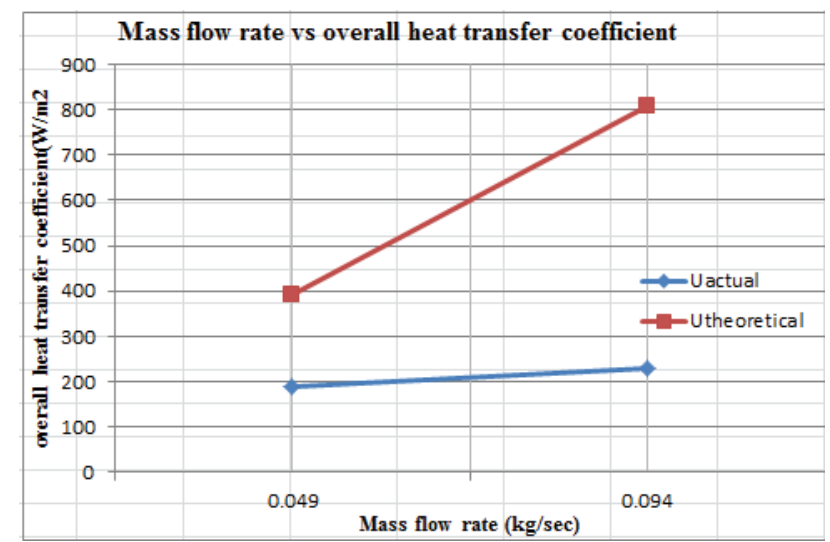

Fig no: 3 Mass flow rate vs overall heat transfer coefficient for parallel flow

\section{SIMULATION RESULTS}

\section{FOR COUNTER FLOW}

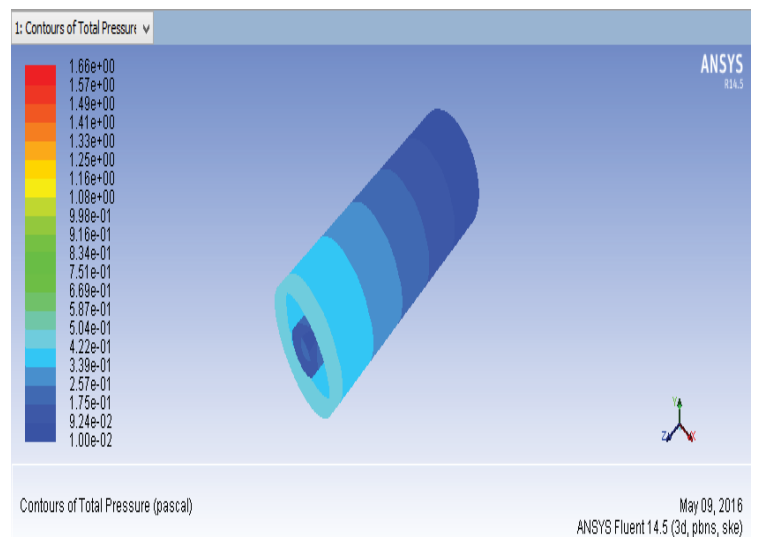

Fig no:5 Contours of Static presssure

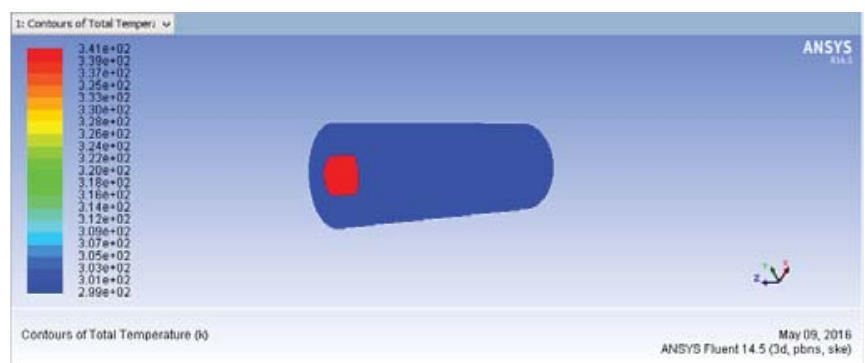

Fig no:7 Countours of Total temperature

SIMULATION RESULTS OF PARALLEL FLOW

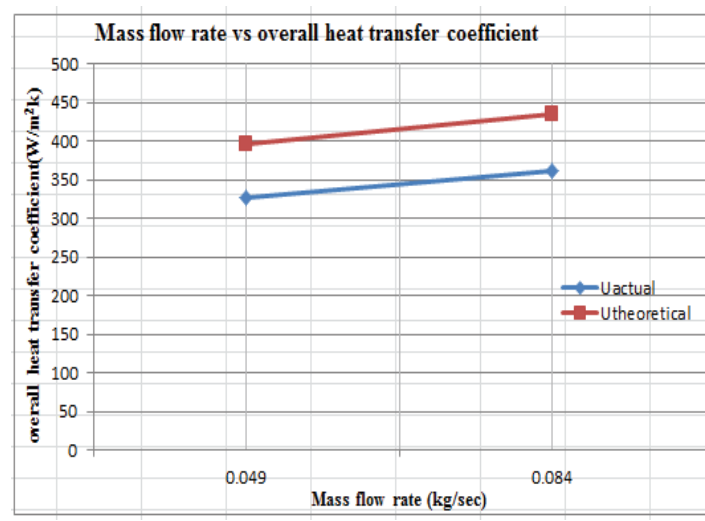

Fig no:4 Mass flow rate vs overall heat transfer coefficient for counter flow

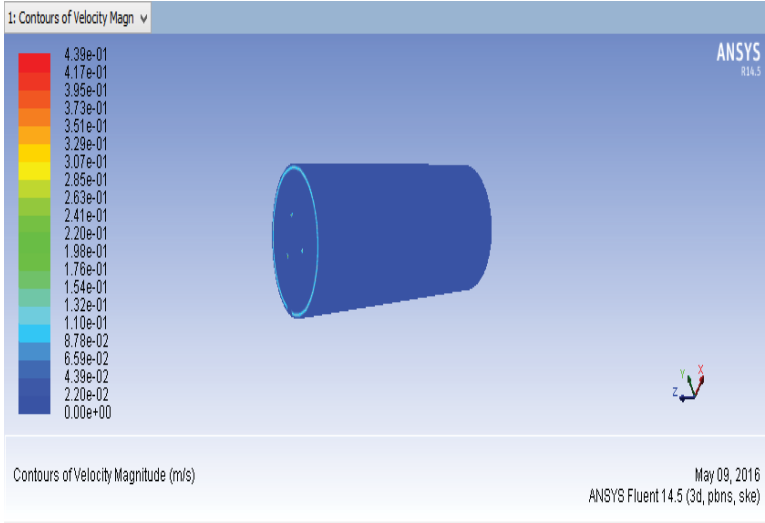

Fig no: 6 Contours of Velocity magnitude 


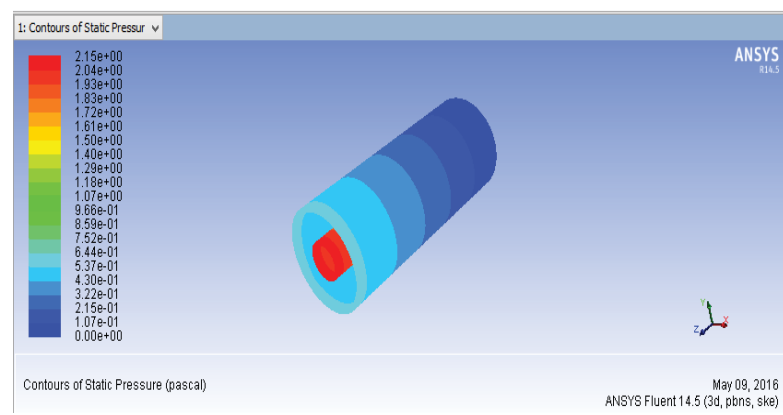

Fig no: 8 Contours of static temperature

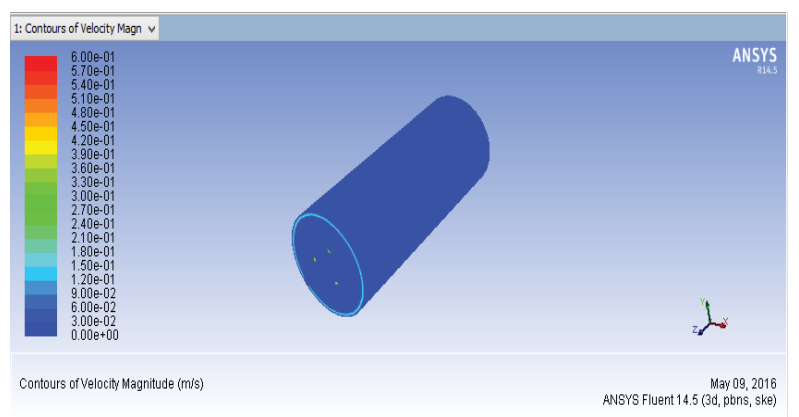

Fig no:10 Contours of velocity magnitude

RESULTS OF SIMULATION FOR COUNTER FLOW

\begin{tabular}{|l|l|l|}
\hline $\begin{array}{l}\text { VARIABLE } \\
\text { NAME }\end{array}$ & MAXIMUM & MINIMUM \\
\hline PRESSURE & $1.7 \mathrm{E}+02$ & $1.00 \mathrm{E}+02$ \\
\hline VELOCITY & $4.39 \mathrm{E}-01$ & $2.20 \mathrm{E}-02$ \\
\hline TEMPERATURE & $3.47 \mathrm{E}+02$ & $2.99 \mathrm{E}+02$ \\
\hline
\end{tabular}

\begin{tabular}{|l|l|l|}
\hline $\begin{array}{l}\text { VARIABLE } \\
\text { NAME }\end{array}$ & MAXIMUM & MINIMUM \\
\hline PRESSURE & $2.15 \mathrm{E}-01$ & $1.07 \mathrm{E}-01$ \\
\hline VELOCITY & $6.00 \mathrm{E}-02$ & $3.00 \mathrm{E}-02$ \\
\hline TEMPERATURE & $3.41 \mathrm{E}+02$ & $2.41 \mathrm{E}+02$ \\
\hline
\end{tabular}

\section{CONCLUSION}

This study presents design and experimental analysis on concentric tube heat exchanger. The experiments were conducted in turbulent region in horizontal tube.

The following conclusions are drawn

1. The average heat transfer coefficient inside tube increases with increase in the flow rate of fluid in each case. Because with increase in flow rate of fluid flowing through the tube the flow velocity increases, which in turn increase the Reynolds number for the fluid.

2. The overall heat transfer coefficient was compared for both parallel and counter flow in theoretical and experimental analysis is found to be less. 


\section{REFERENCES}

[1] Joshi H. M. and Webb R. L. 1987. Heat Transfer and Friction in Offset Strip Fin Heat Exchanger, International Journal of Heat and Mass Transfer. 30(1): 69-80

[2] Suzuki, K.,Hiral, E.,Miyake,Numerical and Experimental studies on a two Dimensional Model of an Offset-Strip-Fin type Compact Heat Exchanger used at low Reynolds Number. International Journal of Heat and Mass Transfer 1985 28(4) 823-836.

[3] Tinaut F. V., Melgar A. and Rehman Ali A. A. 1992 Correlations for Heat Transfer and Flow Friction Characteristics of Compact Plate Type Heat Exchangers. International Journal of Heat and Mass Transfer. 35(7):1659:1665

[4] Manglik and Bergles A. E. 1995 Heat Transfer and Pressure drop Correlations for Rectangular Offset Strip Finn Compact Heat Exchangers. Experimental Fluid Science 10:171-180

[5] Hu S and Herold K.E.1995 Prandtl Number Effect on Offset Strip Fin Heat Exchanger Performance: Predictive Model for Heat Transfer and Pressure Drop. International Journal of Heat and Mass Transfer 38(6) 1043-1051

[6] Zhang L. W., Balachandar S., Tafti D. K. and Najjar F. M. 1997.Heat Transfer Enhancement Mechanisms in Inline and Staggered Parallel Plate Fin Heat Exchanger. International Journal of Heat and Mass Transfer 40(10):2307-2325

[7] Dejong N. C.,Zhang L. W., Jacobi A. M., Balchandar S. and Tafti D. K. 1998. A Complementary Experimental and Numerical Study of Flow and Heat Transfer in Offset Strip Fin Heat Exchangers. Journal of Heat Transfer 12:690:702

[8] Bhowmik H., Kwan- Soo Lee 2009. Analysis of Heat Transfer and Pressure Drop Characteristics in an Offset Strip Fin Heat Exchanger. International Journal of Heat and Mass Transfer 259-263

[9] Saidi A. and Sudden B. 2001.A Numerical Investigation of Heat Transfer Enhancement in Offset Strip Fin Heat Exchangers in Self Sustained Oscillatory Flow. International Journal of Numerical Methods for Heat and Fluid Flow. 11(7): 699-716

[10] Dong J., Chen J., Chen Z. and Zhou Y. 2007.Air Side Thermal hydraulic Performance of Offset Strip Fin Heat Exchangers Fin Alumunium Heat Exchangers. Applied Thermal Engineering 27:306-313 